\title{
CXCL12/CXCR4 signaling counteracts docetaxel-induced microtubule stabilization via p21-activated kinase 4-dependent activation of LIM domain kinase 1
}

\author{
Arun Bhardwaj ${ }^{1,}{ }^{,}$, Sanjeev K. Srivastava ${ }^{1,}{ }^{*}$, Seema Singh ${ }^{1}$, Sumit Arora ${ }^{1}$, Nikhil \\ Tyagi $^{1}$, Joel Andrews ${ }^{1}$, Steven McClellan ${ }^{1}$, James E. Carter ${ }^{2}$, Ajay P. Singh ${ }^{1,3}$ \\ ${ }^{1}$ Department of Oncologic Sciences, Mitchell Cancer Institute, University of South Alabama, Mobile, Alabama, USA \\ ${ }^{2}$ Department of Pathology, College of Medicine, University of South Alabama, Mobile, Alabama, USA \\ ${ }^{3}$ Department of Biochemistry and Molecular Biology, College of Medicine, University of South Alabama, Mobile, Alabama, USA \\ *Authors contributed equally in this manuscript
}

Correspondence to:

Ajay P. Singh, e-mail: asingh@health.southalabama.edu

Keywords: CXCL12/CXCR4, docetaxel, microtubules, PAK4, LIMK1

Received: August 27, $2014 \quad$ Accepted: October 02, 2014

Published: November 11, 2014

\section{ABSTRACT}

Emerging data highlight the significance of chemokine (C-X-C motif) ligand $12 /$ chemokine (C-X-C motif) receptor 4 (CXCL12/CXCR4) signaling axis in the chemoresistance of several malignancies, including prostate cancer (PCa); however, underlying mechanisms remain largely elusive. Here, we demonstrate that CXCL12 treatment rescues the PCa cells from docetaxel (DTX)-induced toxicity by overriding its effect on cell cycle $\left(G_{2} / M\right.$ phase arrest). We further demonstrate that the chemoprotective effect of CXCL12 is abolished upon pharmacological inhibition or RNA interference-mediated silencing of CXCR4. Moreover, microtubule stabilization caused by DTX is suppressed in CXCL12-stimulated PCa cells as revealed by immunofluorescence and immunoblot analyses. The effect of CXCL12 on microtubule stabilization is abrogated when PCa cells are pre-treated with a CXCR4 antagonist. In additional studies, we show that the chemoprotective action of CXCL12/CXCR4 signaling is mediated by p21-activated kinase 4 (PAK4)-dependent activation of Lim domain kinase 1 (LIMK1), and inhibition of either PAK4 or LIMK1 leads to re-sensitization of PCa cells to DTX-induced tubulin polymerization and cellular toxicity even in the presence of CXCL12. Altogether, our findings uncover a novel mechanism underlying CXCL12/CXCR4 signaling-induced PCa chemoresistance and suggest that targeting of this signaling axis or its downstream effector pathway could lead to therapeutic enhancement of DTX.

\section{INTRODUCTION}

Despite enormous scientific advancement over the past few decades, prostate cancer $(\mathrm{PCa})$ still remains the second leading cause of cancer-related death in males in the United States [1]. The American Cancer Society estimates that nearly 233,000 new cases of PCa will be diagnosed and that about 29,480 people will die of this disease this year in the United States [1]. The first line of therapy for metastatic PCa is chemical or medical castration; however, most tumors relapse in castration-resistant (CR) form after an initial response [2, 3]. Standard optional treatment for such patients with symptomatic metastatic CR PCa is docetaxel (DTX)-based chemotherapy, but in most cases it offers survival advantage only for a short period of time $(\sim 3$ months) due to chemoresistance $[4,5]$. Therefore, further research is required to understand the molecular mechanisms underlying DTX-resistance in PCa, which could be helpful in formulating alternative and superior therapeutic strategies.

DTX is a member of the 'taxane' group of chemotherapeutic agents. It binds to the $\beta$-tubulin present in the microtubules (MTs), causing mitotic arrest and 
subsequent apoptosis [6]. Development of DTX-resistance is a common clinical problem; however, underlying mechanisms remain poorly understood. It is suggested that sustained activation of androgen-receptor (AR) signaling in CR disease [7], activation of alternative oncogenic survival pathways (such as EGFR, PI3K/Akt, MAPK/ ERK) $[8,9]$ and overexpression of $\beta$ III-tubulin and/ or drug efflux proteins $[10,11]$ could underlie the DTX therapeutic failure in PCa. More recently, it has also been suggested that tumor microenvironment also plays a major role in cancer chemoresistance as an 'extrinsic de novo' factor [12]. In relation to the tumor microenvironment, pathological involvement of the chemokine (C-X-C motif) ligand 12/chemokine (C-X-C motif) receptor 4 (CXCL12/ CXCR4) signaling axis has been very well documented in several malignancies, including PCa [13-15]. In general, CXCR4 is activated upon binding to its sole ligand, CXCL12, which initiates a series of downstream signaling cascades responsible for downstream phenotypic responses $[15,16]$. Several lines of evidence support the significance of this signaling node in PCa growth, invasion and metastasis [16-18]. Furthermore, a recent study reported that CXCL12 (produced by prostate stromal cells) protected PCa cells from DTX toxicity, an effect that was mediated through CXCR4 activation [19]. However, the mechanistic basis for this observation remained unclear.

In the present study, we have investigated the mechanism underlying chemoprotective action of CXCL12/CXCR4 signaling in PCa. Our data demonstrate that the activation of CXCL12/CXCR4 signaling counteracts DTX-induced $\mathrm{G}_{2} / \mathrm{M}$ phase cell cycle arrest through its effect on microtubule stability. Furthermore, we identify an important role of p21-activated kinase 4 (PAK4)-induced LIM domain kinase 1 (LIMK1) phosphorylation in mediating CXCR4 activation-induced DTX resistance. These novel findings are significant in supporting the utility of the CXCL12/CXCR4 signaling axis as a therapeutic target, and in devising improved therapeutic strategies.

\section{RESULTS}

\section{Activation of CXCL12/CXCR4 signaling relieves docetaxel-induced $\mathrm{G}_{2} / \mathrm{M}$ phase cell cycle arrest}

We first examined the expression of CXCR4 and its sole ligand, CXCL12, in a panel of PCa and normal/ benign prostate epithelial (RWPE1 and 2) cell lines. An aberrant expression of CXCR4 was observed in all PCa cell lines, while no expression was detected in normal/ benign prostate epithelial cells (Figure 1A). Moreover, we observed that PCa cells produced very low level of CXCL12 (range between 0.2 to $1.0 \mathrm{pg} / \mathrm{ml} / 10^{6}$ cells) (data not shown). Next, we treated PCa cells with DTX (0-30 nM) for 24 and $48 \mathrm{~h}$ and examined its toxicity. The data show that low CXCR4-expressing LNCaP cells are relatively more sensitive to DTX toxicity as compared to high CXCR4-expressing PCa cell lines (C4-2, PC3 and DU145) (Figure 1B). It should, however, be noted that the expression level of CXCR4 in PCa cell lines does not precisely correlate with docetaxel sensitivity, which could be due to the presence of additional resistance mechanisms. Nonetheless, we observe that the silencing (using specific siRNAs; Figure 1C) or inhibition (by AMD3100) of CXCR4 leads to abrogation of CXCL12induced chemo-protection of CXCR4 in C4-2 and PC3 cells (Figure 1D and 1E). In next set of experiments, we examined whether activation of CXCL12/CXCR4 signaling axis had any effect on DTX-induced $\mathrm{G}_{2} / \mathrm{M}$ phase cell cycle arrest, which is an established mechanism of chemotoxic action of docetaxel [20]. C4-2 and PC3 cells were treated with DTX alone or in presence of CXCL12 and/or AMD3100, and analyzed by flow cytometry for their cell cycle distribution. Consistent with previous reports [20], the data show an arrest of cells in $\mathrm{G}_{2} / \mathrm{M}$ phase of cell cycle upon DTX treatment. We observe that $61.6 \%$ and $62.1 \%$ of DTX-treated C4-2 and PC3 cells, respectively, were present in $\mathrm{G}_{2} / \mathrm{M}$ phase as compared to $11.52 \%$ and $16.0 \%$ of control (vehicle treated) C4-2 and PC3 cells, respectively (Figure 2). Interestingly, our data demonstrate that CXCL12 treatment rescued the $\mathrm{PCa}$ cells from DTX-induced $\mathrm{G}_{2} / \mathrm{M}$ mitotic arrest, and this effect was abolished upon pretreatment of PCa cells with AMD3100 (Figure 2). Altogether, our results suggest that CXCL12/CXCR4 relieves DTX-induced $\mathrm{G}_{2} / \mathrm{M}$ phase cell cycle arrest in PCa cells and, thus may protect them from the cytotoxic effect of DTX.

\section{CXCL12/CXCR4 signaling counteracts docetaxel-induced microtubule stabilization}

DTX is a microtubule-stabilizing agent, which causes mitotic arrest following binding to polymerized tubulins and subsequent blockage of their depolymerization $[6,21]$. Therefore, we investigated if CXCL12/CXCR4 signaling had an effect on DTX-induced stabilization of microtubules. For this, we performed immunofluorescence staining using an antibody against detyrosinated (glu-) tubulin, a specific marker of polymerized tubulin [22] on PCa cells either untreated or treated with DTX alone or in the presence of CXCL12. Our data demonstrate that PCa cells treated with DTX exhibit extensive formation of microtubules, an effect that is almost completely abrogated in CXCL12-treated cells (Figure 3A). Furthermore, our data show that the pre-treatment of PCa cells with a CXCR4 antagonist, AMD3100, neutralizes the effect of CXCL12 and thus restores the stabilization of microtubules (Figure 3A). To further confirm these findings, we examined the expression of tubulin polymerization markers [glu- and acetylated (ace-) tubulin] by immunoblot assay. Our data show an increased expression of both glu- and ace- tubulin in 
A.

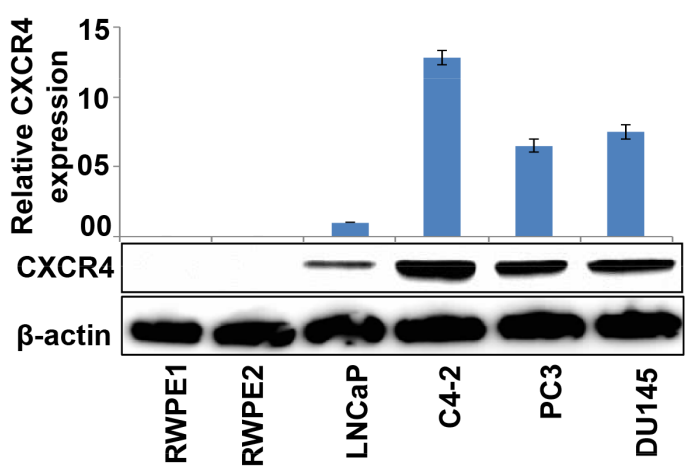

B.

\begin{tabular}{l|c|c}
\multirow{2}{*}{$\begin{array}{l}\text { Cell } \\
\text { lines }\end{array}$} & \multicolumn{2}{|c}{$\begin{array}{c}\mathbf{I C}_{50} \text { values of docetaxel in } \\
\text { prostate cancer cells at } \\
\text { different time points }\end{array}$} \\
\cline { 2 - 3 } & $\mathbf{2 4 \mathbf { h }}$ & $\mathbf{4 8 ~} \mathbf{h}$ \\
\hline LNCaP & $12.9 \mathrm{nM}$ & $5.2 \mathrm{nM}$ \\
\hline $\mathbf{C 4 - 2}$ & $18.5 \mathrm{nM}$ & $13.2 \mathrm{nM}$ \\
\hline PC3 & $>30.0 \mathrm{nM}$ & $19.3 \mathrm{nM}$ \\
\hline DU145 & $16.3 \mathrm{nM}$ & $12.1 \mathrm{nM}$
\end{tabular}

C.
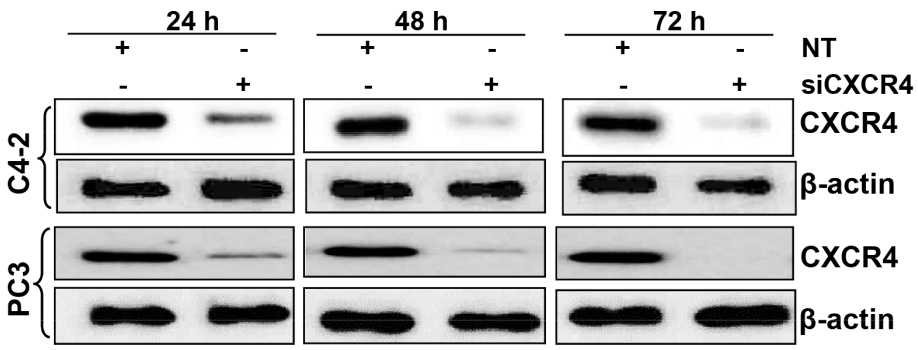
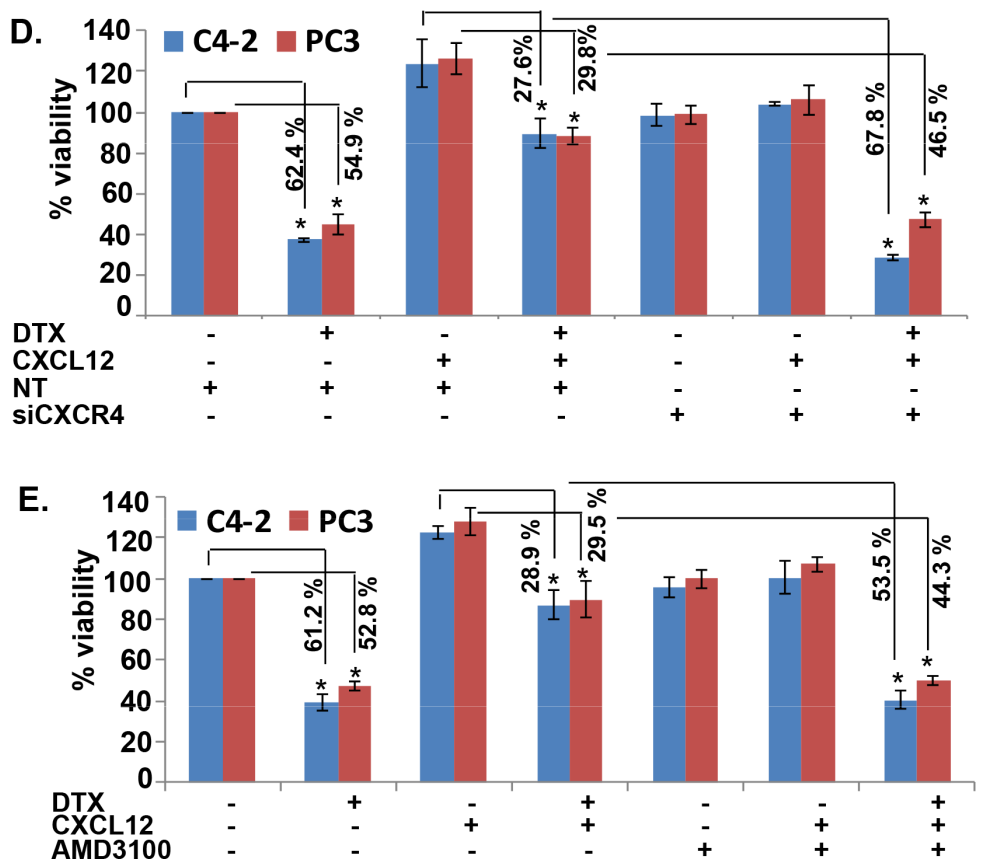

Figure 1: CXCR4 is overexpressed in prostate cancer cells and imparts docetaxel resistance upon CXCL12 stimulation. (A) Total protein from normal prostate epithelial and various PCa cell lines was isolated and resolved by electrophoresis. Thereafter, expression of CXCR4 was examined by immunoblot analysis. $\beta$-actin was used as an internal control. (B) PCa cells were treated with the various doses of docetaxel (DTX; 0-30 nM) and the viability of cells at different time intervals (24 and $48 \mathrm{~h}$ ) was examined by WST-1 assay and $\mathrm{IC}_{50}$ was calculated. (C) PCa cells were grown in 6-well plate and transiently transfected with non-target (NT), CXCR4targeted siRNAs for 24-72 h. After treatment, total protein was isolated and subjected to immunoblot analysis to assess the expression of CXCR4. $\beta$-actin was used as an internal control. (D) C4-2 and PC3 cells were grown in 96 well plate. Thereafter, cells were treated with either CXCR4 targeting siRNAs or non-targeting control (NT-siRNA). After $24 \mathrm{~h}$ of transfection cells were treated with DTX (20 nM) in absence or presence of CXCL12 $(100 \mathrm{ng} / \mathrm{mL})$ and growth was monitored by WST-1 assay after $48 \mathrm{~h}$. (E) C4-2 and PC3 cells were treated with the AMD3100 $(5 \mu \mathrm{g} / \mathrm{mL})$, a CXCR4 antagonist, $1 \mathrm{~h}$ prior to the treatment of CXCL12 followed by DTX treatment. After $48 \mathrm{~h}$ of treatment, viability of cells was examined by WST-1 assay. Data is presented as mean \pm S.D., $\mathrm{n}=3 ;{ }^{*} p<0.01$.

DTX-treated cells, which is suppressed in cells co-treated with CXCL12. Similarly, the pre-treatment of PCa cells with AMD3100 overrides the suppressive effect of CXCL12 (Figure 3B). Taken together, these findings demonstrate that the activation of CXCL12/CXCR4 signaling rescues the PCa cells from DTX-induced $\mathrm{G}_{2} / \mathrm{M}$ phase cells cycle arrest by counteracting its effect on microtubule stabilization.

\section{Inhibition of LIMK1 abrogates the effects of CXCL12 on docetaxel sensitivity and microtubule dynamics}

We next explored the molecular mechanisms by which activation of CXCL12/CXCR4 signaling counteracts DTX-induced microtubule stabilization. Our specific focus was LIMK1, which is an important downstream effector of CXCL12/CXCR4 signaling [23] and is known to regulate the stability of microtubules through direct binding [24]. Our data show that the phosphorylation of LIMK1 is increased in a time-dependent manner following CXCL12 stimulation in $\mathrm{PCa}$ cells (Figure 4A). Moreover, we observe that CXCL12-induced LIMK1 phosphorylation is abrogated following pretreatment with AMD3100, thus, suggesting that this effect is mediated through CXCR4 activation (Figure 4B). In next set of experiments, we treated PCa cells with LIMKi3, a LIMK1 inhibitor; prior to the treatment with CXCL12 and/or DTX and determined its effect on overall cell survival and stability of microtubules. 

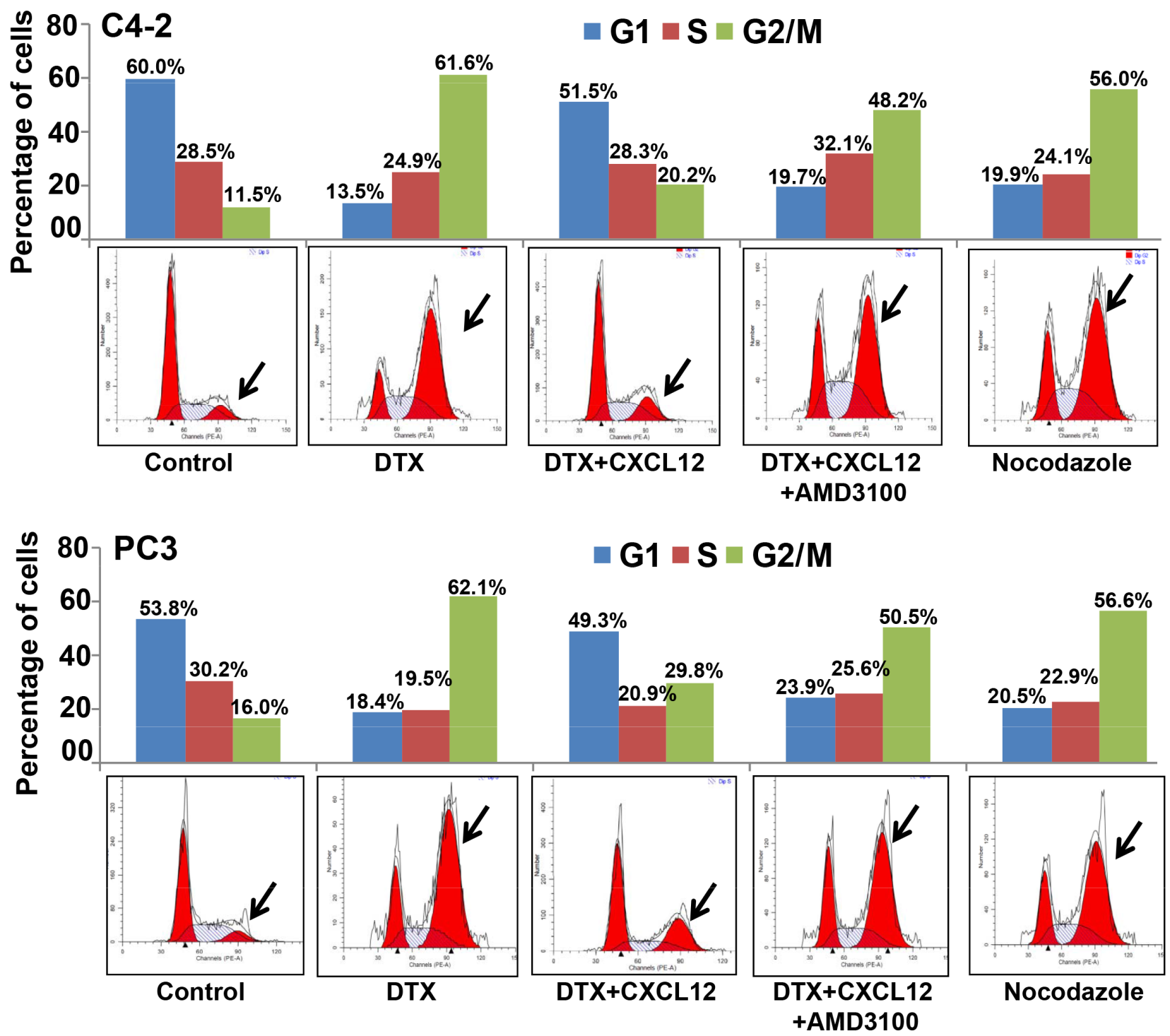

Figure 2: Activation of CXCL12/CXCR4 signaling relieves docetaxel-induced $\mathbf{G}_{2} / \mathbf{M}_{\text {cell }}$ cycle arrest. Synchronized C4-2 and PC3 cells were treated with PBS (vehicle control), docetaxel (DTX; $20 \mathrm{nM}$ ) alone or in combination with AMD3100 (5 $\mu \mathrm{g} / \mathrm{mL})$ and/ or CXCL12 (100 ng/mL). After $24 \mathrm{~h}$ of treatment cells were fixed, stained with propidium iodide and analyzed using flow cytometry. Data show a $\mathrm{G}_{2} / \mathrm{M}$ phase-arrest in DTX-treated cells. CXCL12 abrogated DTX-induced $\mathrm{G}_{2} / \mathrm{M}$ arrest, which was reversed in the cells pre-treated with AMD3100. Nocodazole $(1 \mu \mathrm{M})$ was used as positive control.

Our data demonstrate that inhibition of LIMK1 neutralizes the rescue effect of CXCL12/CXCR4 signaling on DTXinduced cytotoxicity in both PCa cell lines (Figure 4C). The data also show that the inhibition of LIMK1 leads to abrogation of the counteracting effect of CXCL12/CXCR4 signaling on the DTX-induced microtubule stabilization (Figure 4D). Moreover, our data from immunoprecipitation assay reveal a direct interaction of LIMK1 with tubulin, which is decreased upon CXCL12 stimulation (Figure 4E). Together, these findings suggest that CXCL12/CXCR4signaling impedes DTX-induced microtubule stabilization by promoting the phosphorylation-mediated dissociation of LIMK1 from microtubules.

\section{Activation of LIMK1 by CXCL12/CXCR4 signaling is mediated through PAK4}

Having observed a role of LIMK1 in CXCL12/ CXCR4 signaling-induced DTX resistance, we next sought to identify the protein kinase involved in its phosphorylation. For this, we focused on PAK4, which is known to cause LIMK1 phosphorylation [25]. The data show that CXCL12 treatment induces the phosphorylation of PAK4 in a time-dependent manner, which is abrogated upon pre-treatment of $\mathrm{PCa}$ cells with a CXCR4 antagonist (AMD3100) (Figure 5A and B). Next, we investigated if PAK4 mediates the 

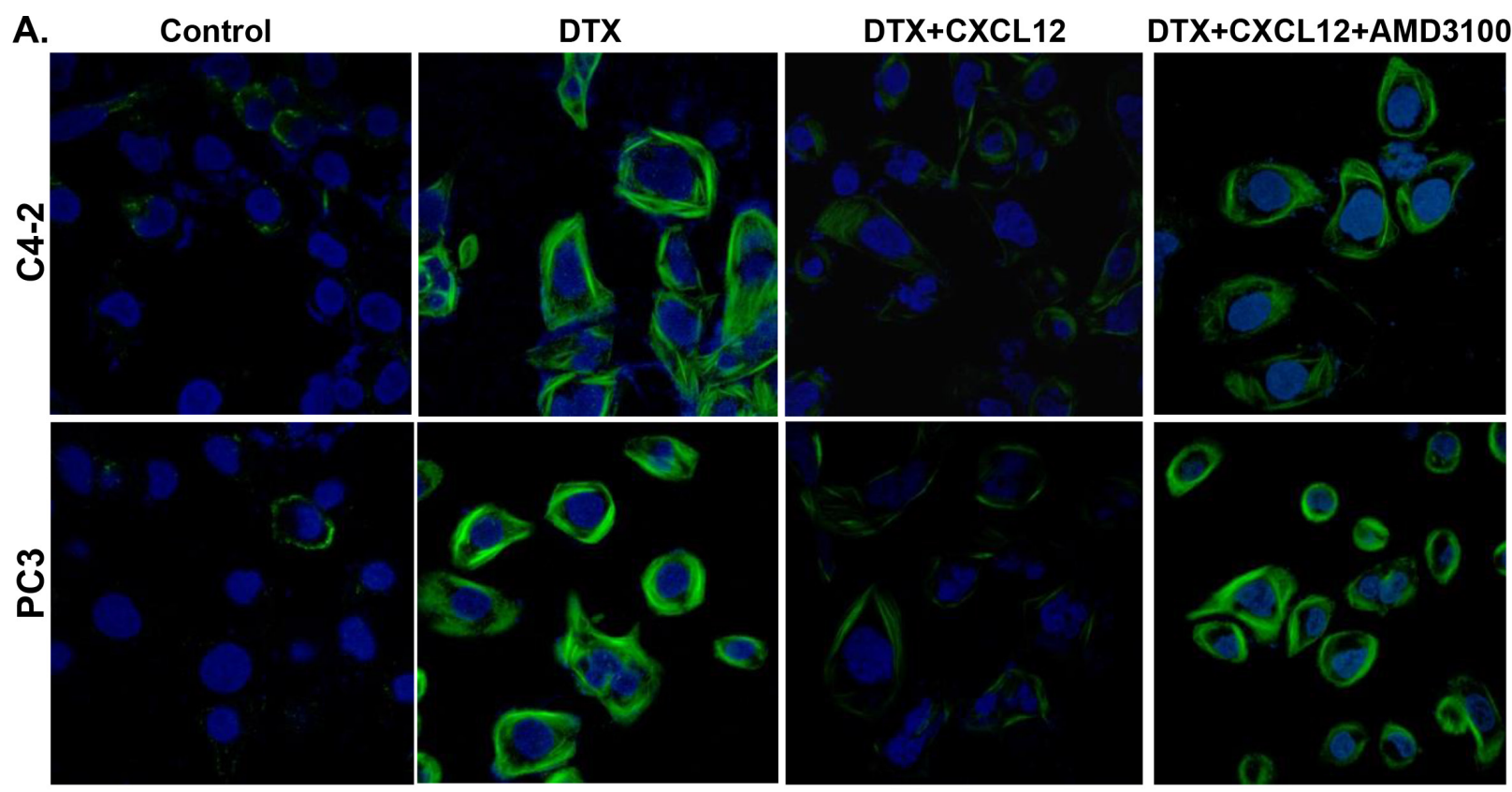

B.
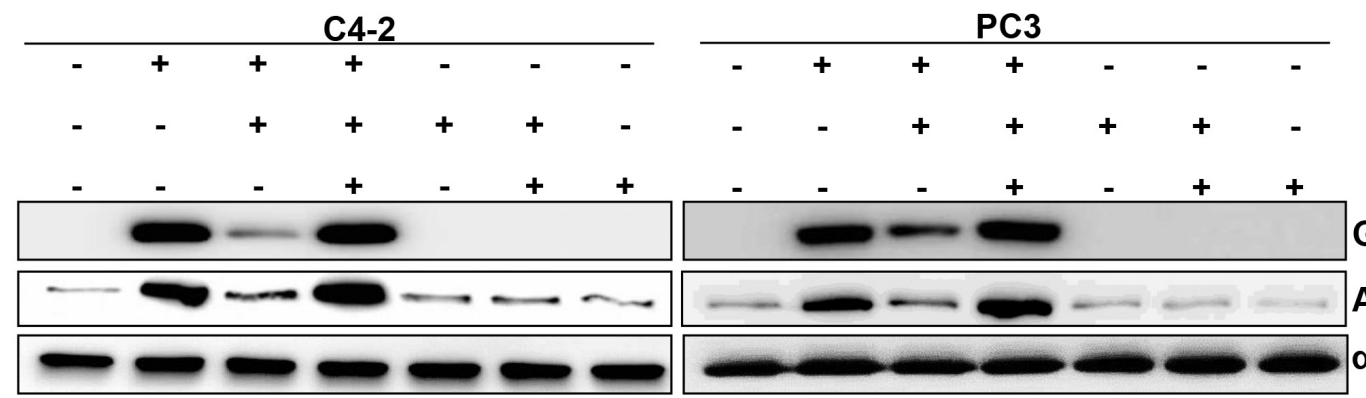

DTX

CXCL12

AMD3100

Glu-tubulin

Ace-tubulin

$\alpha$-Tubulin

Figure 3: Effect of CXCL12/CXCR4 signaling on the docetaxel-induced microtubules stabilization. (A) PCa cells (C4-2 and PC-3) were grown on glass bottom plate and treated with PBS (vehicle control), DTX alone or in combination with pre-treatment of AMD3100 $(5 \mu \mathrm{g} / \mathrm{mL})$ and $/$ or CXCL12 $(100 \mathrm{ng} / \mathrm{mL})$. After $24 \mathrm{~h}$ of treatment, cells were fixed, stained using glu-tubulin and examined under confocal microscope. (B) Total protein was collected from the PCa cells treated with DTX alone or in combination with pre-treatment of AMD3100 and/or CXCL12 for $24 \mathrm{~h}$. Thereafter, expression of detyrosinated (Glu), acetylated (Ace) and total $\alpha$-tubulin was examined by immunoblot analysis.

phosphorylation of LIMK1 in response to CXCL12 treatment. For this, PAK4 was silenced using specific siRNAs prior to CXCL12 stimulation and its effect on LIMK1 phosphorylation was examined. We observed substantial silencing of PAK4 after $24 \mathrm{~h}$ of transfection in both the PCa cell lines treated with siPAK4 and this effect was sustained at least until $72 \mathrm{~h}$ of transfection (data not shown). Furthermore, we observed that the effect of CXCL12 on LIMK1 phosphorylation was abolished in PAK4-silenced PCa cells (Figure 5C). Our data also reveal that the effect of CXCL12/CXCR4 signaling on DTX-induced microtubule stabilization is nullified upon silencing of PAK4 in PCa cells (Figure 5D). Together, these data suggest that CXCL12induced LIMK1 phosphorylation and DTX-resistance is mediated through PAK4 in PCa cells through its effect on microtubule stability.

\section{DISCUSSION}

The present study provided mechanistic support for the chemoprotective action of CXCL12/CXCR4 signaling against DTX toxicity in PCa cells. CXCL12/ CXCR4 signaling-induced DTX-resistance was caused by overriding the effect of DTX on cell cycle $\left(\mathrm{G}_{2} / \mathrm{M}\right.$ phase arrest) due to its counteracting effect on DTX-induced microtubule stabilization. Additionally, we observed that PAK4-mediated LIMK1 activation was important in the rescue effect of CXCL12/CXCR4 signaling on DTX toxicity.

Overexpression of CXCR4 in $\mathrm{PCa}$ and its association with poor patients' survival has been well reported [13]. It has also been demonstrated that CXCL12/ CXCR4 signaling plays an important role in the invasion and metastasis of PCa cells [16, 18], which ultimately 

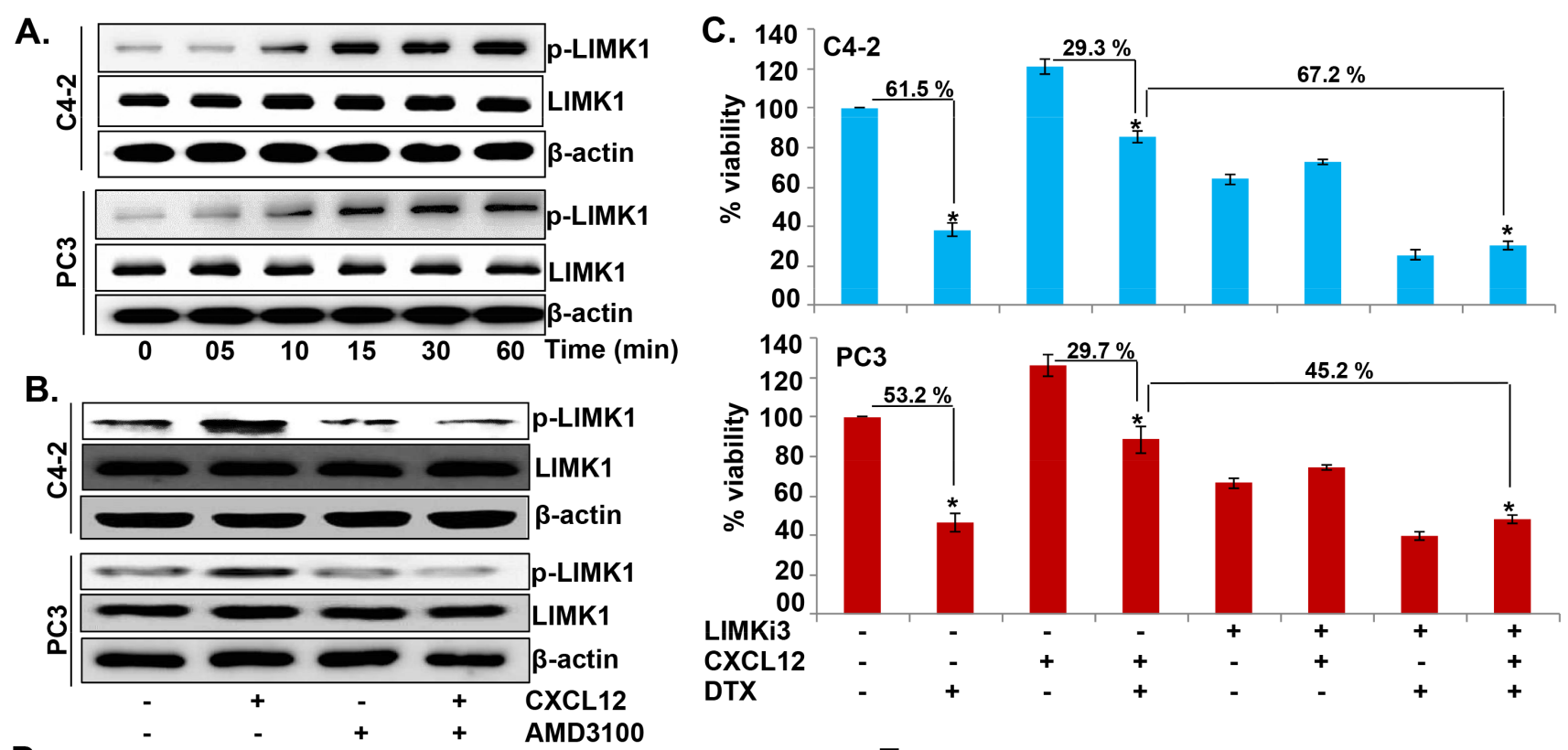

D.
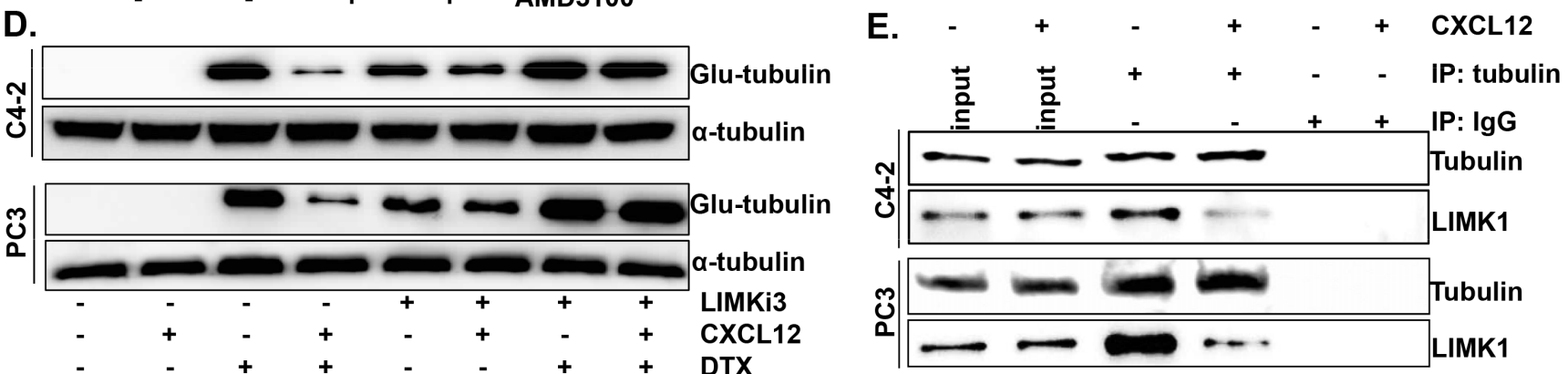

Figure 4: LIMK1 mediates CXCL12/CXCR4-induced destabilization of microtubules and docetaxel resistance. (A) Cells were grown in 6-well plate and treated with CXCL12 $(100 \mathrm{ng} / \mathrm{mL})$ for various time intervals $(0-60 \mathrm{~min})$. Post treatment total protein was collected and expression of p-LIMK1 and total-LIMK1 was determined by immunoblot analysis. (B) Cells were pretreated with AMD3100 $(5 \mu \mathrm{g} / \mathrm{mL}) 1 \mathrm{~h}$ prior to the CXCL12 treatment $(100 \mathrm{ng} / \mathrm{mL})$. After $60 \mathrm{~min}$, effect on the expression of p-LIMK1 and totalLIMK1 was examined by immunoblot assay. $\beta$-actin was used as an internal control. (C) PCa cells were seeded in 96 well plate and treated with PBS (vehicle control), LIMKi3 $(25 \mu \mathrm{M})$, CXCL12 $(100 \mathrm{ng} / \mathrm{mL})$ and DTX $(20 \mathrm{nM})$ alone or in combination. After $48 \mathrm{~h}$ of treatment cell viability was measured by WST-1 assay. Data (mean $\pm \mathrm{SD} ; \mathrm{n}=3$ ) presented as change in cell viability as compared to the control cells, ${ }^{*} p<0.01$. (D) C4-2 and PC3 cells grown in 6-well plate were treated with LIMKi3 $(25 \mu \mathrm{M})$ for $2 \mathrm{~h}$, prior to the CXCL12 $(100 \mathrm{ng} / \mathrm{mL})$ and subsequent DTX $(20 \mathrm{nM})$ treatment alone or in combination as described earlier. Post treatment total protein was collected and immunoblot analysis was performed to examine the expression of Glu-tubulin. $\alpha$-tubulin was used as an internal control. (E) Immuno-precipitation assay with anti-tubulin (mouse $\mathrm{mAb}$ ) or normal mouse $\mathrm{IgG}$ antibodies using the total cell lysates from control and with CXCL12-stimulated (for $30 \mathrm{~min}$ ) PCa cells was performed. Thereafter, immuno-precipitated proteins were resolved by electrophoresis and subjected to immunoblot analysis for tubulin and LIMK1.

promotes DTX-resistance in PCa [7]. Moreover, a recent study performed by Domanska et al. provides direct support to our findings, in which they have also shown the chemoprotective role of CXCL12/CXCR4 signaling in PCa cells [19]. Furthermore, Hatano et al. have reported that the DTX-mediated activation of the CXCR4, ERK1/2, and c-Myc signaling loop provides survival advantage to the PCa cells in the presence of DTX [26]. Furthermore, a role of CXCR4 signaling in the ligand-independent activation of AR has also been demonstrated, which could indirectly promote DTX-resistance by promoting cell survival [27]. Our findings further add to the list of this supporting literature by providing mechanistic support for a chemoprotective role of CXCL12/CXCR4 signaling in PCa. Our data also provide support to the notion that CXCL12/CXCR4 signaling serves as the common molecular link for the metastatic and therapy-resistant nature of the PCa cells.

We observed that the treatment with CXCL12 effectively relieved DTX-induced $\mathrm{G}_{2} / \mathrm{M}$ phase cell cycle arrest, an effect that was mediated through CXCR4. DTX induced $\mathrm{G}_{2} / \mathrm{M}$ phase arrest is mediated by inhibiting the microtubule depolymerization [20]. Microtubules are polymeric cytoskeletal structures made up of 
A.

C4-2
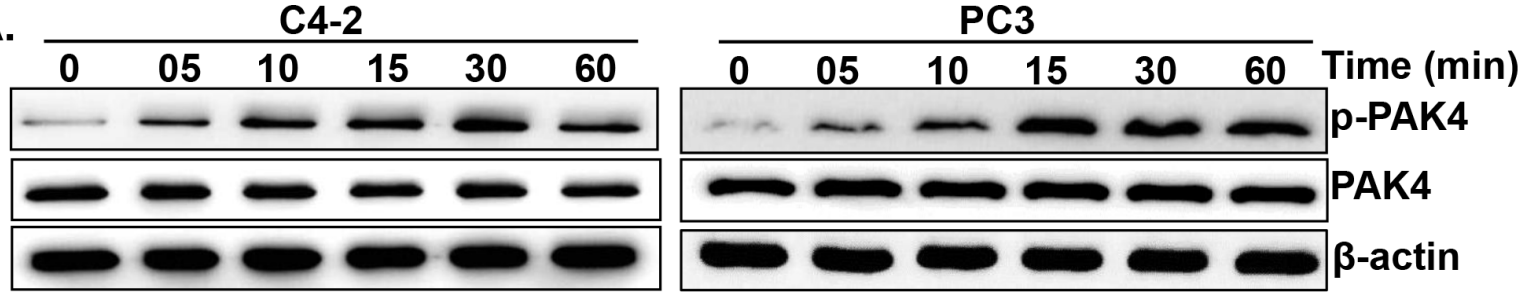

B.

C4-2
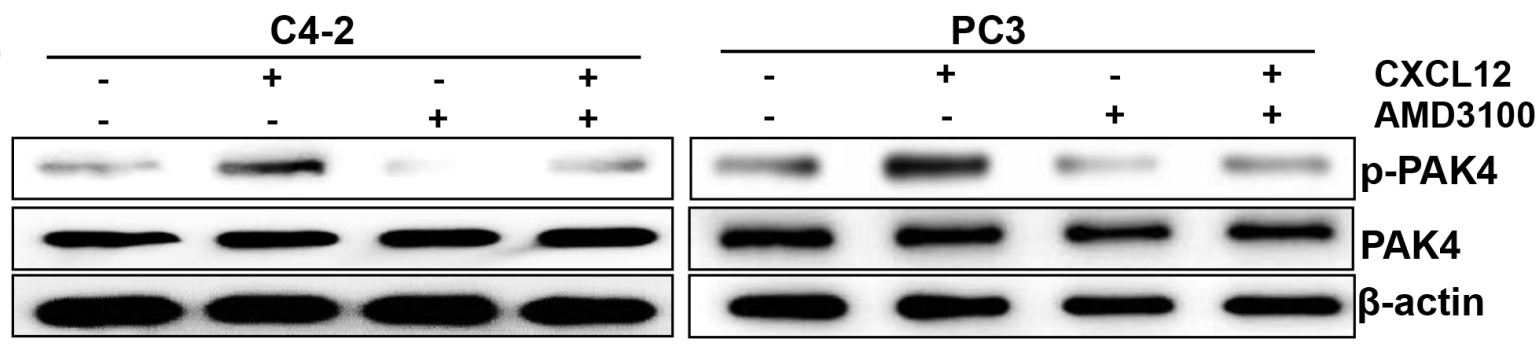

C.
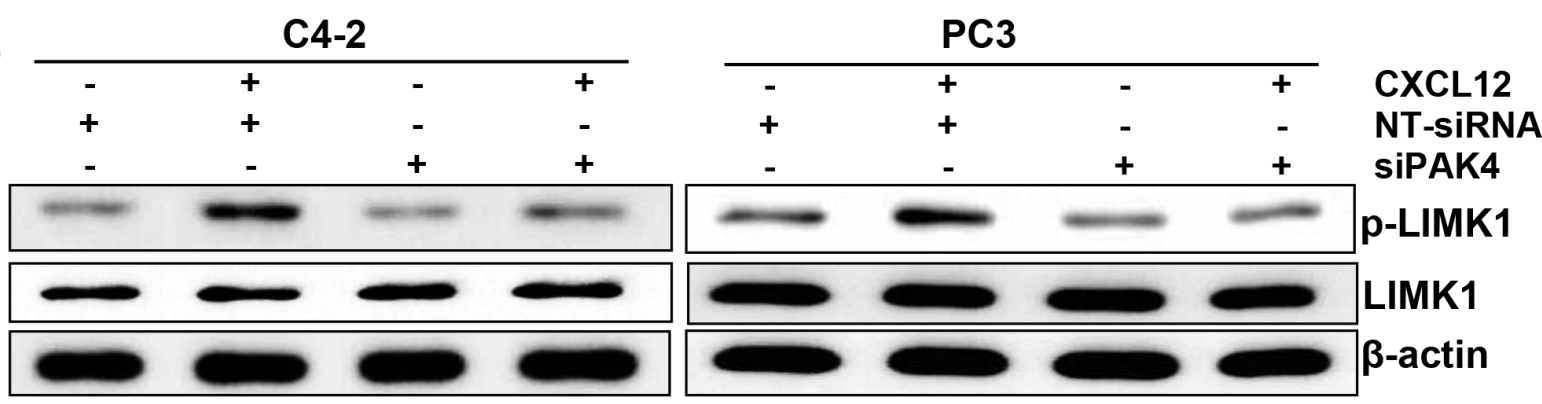

D.
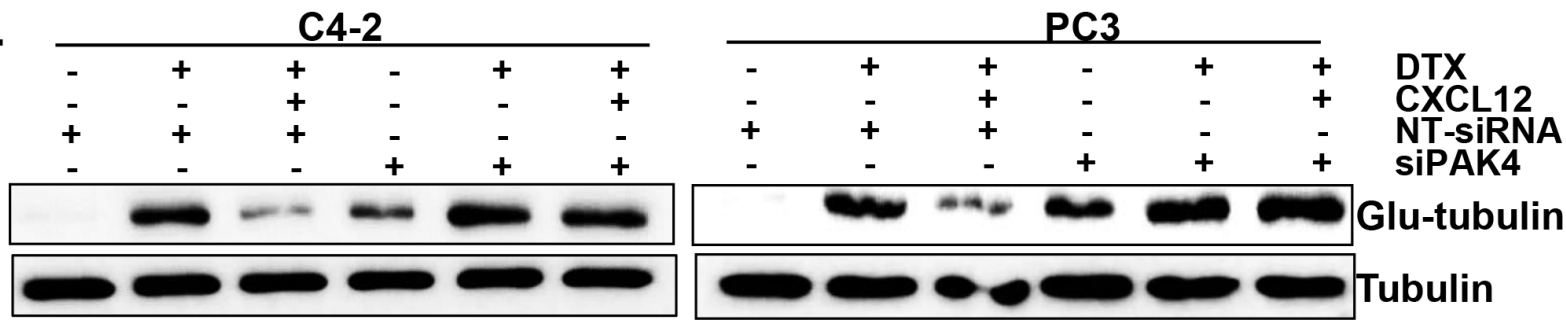

Figure 5: PAK4 is involved in CXCL12/CXCR4-induced LIMK1 phosphorylation. (A) C4-2 and PC3 cells were grown in 6-well plate and treated with CXCL12 $(100 \mathrm{ng} / \mathrm{mL})$ for various time intervals (0-60 min). Thereafter, total protein was isolated, resolved, and subjected to immunoblot analysis to determine the expression of p-PAK4 and total-PAK4. (B) Cells were treated with AMD3100 $(5 \mu \mathrm{g} / \mathrm{mL}) 1 \mathrm{~h}$ prior to the CXCL12 $(100 \mathrm{ng} / \mathrm{mL})$ treatment for $30 \mathrm{~min}$ and, effect on the expression of p-PAK4 and total-PAK4 examined by immunoblot assay. (C) C4-2 and PC3 cells were transfected with PAK4 targeting or non-targeting siRNAs (NT-siRNA). After 24 h of transfection, cells were treated with CXCL12 for $60 \mathrm{~min}$. Post treatment, phosphorylation status of LIMK1 was determined by immunoblot assay. (D) PCa Cells were transfected with PAK4 specific- or NT -siRNAs prior to the DTX $(20 \mathrm{nM})$ and CXCL12 (100 ng/mL) treatment. After $24 \mathrm{~h}$ of treatment total protein was isolated and expression of glu-tubulin was examined by immunoblot assay. $\beta$-actin was used as an internal control

$\alpha$ - $\beta$-tubulin heterodimers and play an important role in the chromosomal segregation during mitosis [21, 28]. In relation to this, our data revealed that the CXCL12mediated activation of CXCR4 counteracted DTXinduced microtubule stabilization in $\mathrm{PCa}$ cells. This finding is supported by an earlier study, in which a role of CXCL12/CXCR4 signaling has been demonstrated in the regulation of microtubule dynamics of immune cells [29]. Furthermore, indirect support comes from another prior report demonstrating the induction of mitotic catastrophe in ovarian cancer cells upon inhibition of CXCR4 activation [30].

Microtubules are highly dynamic structures and their intracellular dynamicity is tightly regulated by various microtubule-associated proteins (MAPs). MAPs physically interact with microtubules and promote their stabilization and/or destabilization [31]. In our study, we observed that the phosphorylation of LIMK1 was increased in PCa cells upon CXCL12 stimulation. Furthermore, data from our immunoprecipitation study 


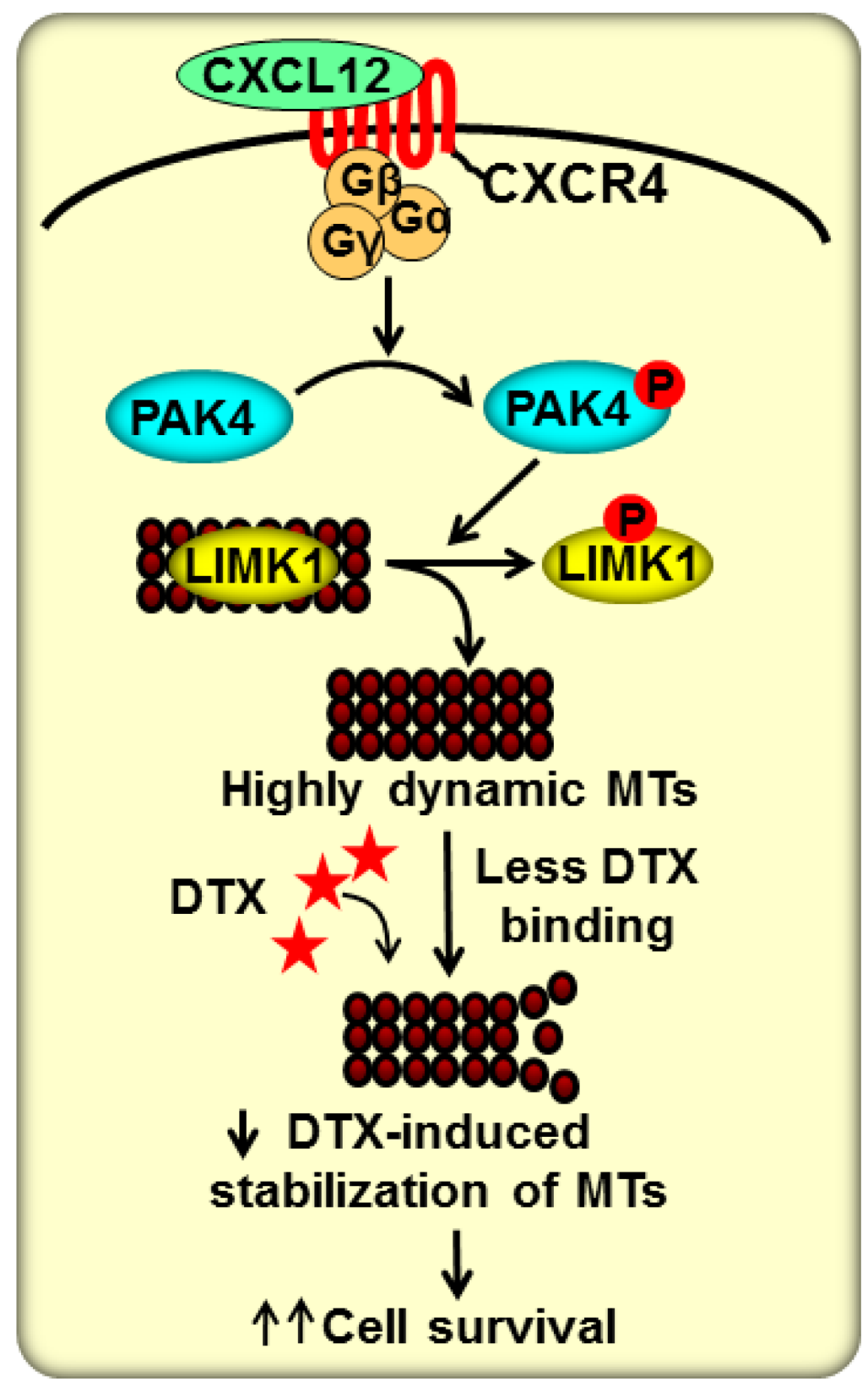

Figure 6: Schematic diagram for the role of CXCL12/CXCR4 and its downstream signaling in DTX resistance. CXCR4 is activated upon binding to its sole ligand, CXCL12, which then leads to PAK4 phosphorylation. Activated PAK4 phosphorylates LIMK1 causing its dissociation from microtubules (MTs) and thus enhancing dynamicity of MTs. In this state, MTs are less likely to bind to DTX and consequently less susceptible to DTX-mediated stabilization. This results in suppression of anti-mitotic effect of DTX and promotes tumor cell survival.

revealed a physical interaction between LIMK1 and tubulin, which is decreased upon CXCL12 stimulation of PCa cells. We further observed that the inhibition of LIMK1 abolished the protective effects of CXCL12/CXCR4 signaling on DTX-induced cytotoxicity as well as on microtubule stabilization. A similar finding is reported in a recent study, where inhibition of LIMK1 in HeLa cells promoted stabilization of microtubules and subsequently led to the cell death [24]. Together, these data suggest that LIMK1 acts as a MAP in its unphosphorylated state to promote the stability of microtubules.

CXCL12/CXCR4 signaling has been shown to activate a number of downstream signaling molecules, which are involved in the regulation of growth, aggressive phenotypes and therapy resistance 
in cancer cells [14-16]. Here, we observed increased phosphorylation of PAK4, a member of the p21-activated kinases (PAKs) family, in CXCL12-treated PCa cells. In concordance with our data, previously Haddad et al. 2001 have also reported the increased activity of PAK4 in CXCL12 stimulated T lymphocytes [32]. To date, the exact molecular mechanism(s) of CXCL12/CXCR4mediated PAK4 activation is not clear. However, the roles of several proteins kinases such as $\mathrm{Rac} / \mathrm{Cdc} 42$, $\mathrm{PI} 3 \mathrm{~K} / \mathrm{Akt}$, PKC, which are the downstream effectors of CXCL12/CXCR4 signaling, have been identified in the activation of PAK4 [33]. In a recent study, Park et al. identified an association of PAK4 activation with increased tumorigenic potential and therapy resistance of PCa cells [34]. Furthermore, our data provide strong evidence that silencing of PAK4 abrogates the effects of CXCL12 on LIMK1 phosphorylation and microtubule dynamics, and thus promotes re-sensitization of the $\mathrm{PCa}$ cells to DTX toxicity. PAK4 interaction with LIMK1 leading to its enhanced phosphorylation has also been reported previously [25] along with demonstration of its pathological significance in PCa [35]. In the same line, our findings now shed new light on the importance of this PAK4-LIMK1 axis and establish it as an essential mediator in the chemoprotective action of the CXCL12/ CXCR4 signaling pathway.

In summary, our research findings have demonstrated an important role of the CXCL12/CXCR4 signaling axis in DTX-resistance of PCa cells through a novel mechanism (Figure 6). This new information provides additional support towards the candidacy of this signaling node as a useful target for PCa therapy.

\section{MATERIALS AND METHODS}

\section{Cell lines, antibodies and siRNAs}

All the cell lines used in this study were obtained, cultured and validated as described earlier [36]. Anti-CXCR4 (rabbit polyclonal), anti-detyrosinated-tubulin (glu-tubulin) and anti-acetylated-tubulin (ace-tubulin) antibodies (mouse monoclonal) were from Abcam (Cambridge, MA). Anti-phospho-LIMK1, anti-LIMK1, anti-PAK4 (rabbit polyclonal) and anti-phospho PAK4 (mouse monoclonal) antibodies were purchased from Cell Signaling Technology (Beverly, MA). Anti- $\alpha$-tubulin (mouse monoclonal; for immunoprecipitation and rabbit polyclonal; for immunoblot), normal mouse IgG and all horseradish peroxidase (HRP)-conjugated secondary antibodies were from Santa Cruz Biotechnology (Santa Cruz, CA). $\beta$-actin antibody (mouse monoclonal) was from Sigma-Aldrich (St. Louis, MO). Non-target (ON-TARGET plus Non-targeting pool) and CXCR4 and PAK4 specific (ON-TARGET plus SMART pool) siRNAs and transfection reagent (DharmaFECT) were from Dharmacon (Lafayette, CO).

\section{Treatments and transfection}

PCa cells were grown in 96- and/or 6- well plates and allowed to attain $60-70 \%$ confluence. Thereafter, cells were treated with DTX (LC labs, Woburn, MA) in the presence or absence of CXCL12 (100 ng/mL) (R\&D Systems, Minneapolis, MN) as indicated in the pertinent figure legends. To dissect the role of CXCR4 and LIM kinase 1, cells were pre-incubated for $1 \mathrm{~h}$ with AMD3100 (CXCR4 antagonist; $5 \mu \mathrm{g} / \mathrm{mL}$ ) (SigmaAldrich) and LIMKi3 (LIM kinase 1 inhibitor; $25 \mu \mathrm{M}$ ) (EMD Millipore, Billerica, MA), respectively. For the knockdown of CXCR4 and PAK4, cells were cultured in 6-well plates and transiently transfected with $50 \mathrm{nM}$ of non-target or target-specific siRNAs using DharmaFECT as per the manufacturer's protocol.

\section{Cell growth assay}

Cells were seeded in 96 well plate $\left(3 \times 10^{3}\right.$ cells/well $)$ a day prior to treatment. Cell growth was then examined after 24 and $48 \mathrm{~h}$ of treatment using WST-1 assay kit (Roche Applied Science, Indianapolis, IN) and percent growth was calculated as described previously [37].

\section{Immunoblot analysis}

Total cells protein was extracted using NP-40 lysis buffer supplemented with protease and phosphatase inhibitors and western blotting was performed as described earlier [38]. Immunodetection was carried out using specific primary antibodies $(1: 1000)$. Thereafter, blots were incubated with respective HRP-labeled secondary antibodies (1:2500), washed and processed with ECL plus ${ }^{\circledR}$ Western Blotting detection kit (Thermo Scientific, Logan, UT) and the signal detected using an LAS-3000 image analyzer (Fuji Photo Film Co., Tokyo, Japan).

\section{Cell cycle analysis}

Cells were synchronized by two courses of incubation (for $48 \mathrm{~h}$ ) in serum-deprived culture media with intermittent culturing (for $24 \mathrm{~h}$ ) in serum-containing media and then various treatments were performed. After $24 \mathrm{~h}$ of treatment (as indicated in figure legend), cells were washed, trypsinized and fixed with $70 \%$ ethanol overnight at $4{ }^{\circ} \mathrm{C}$. Cells were then washed with cold PBS, stained using PI/RNase kit (BD Bio Sciences, San Jose, CA) and analyzed by flow-cytometry on a BD-FACS Canto ${ }^{\mathrm{TM}}$ II (BD Bio Sciences). The percentage of cell population in various phases of cell cycle was calculated using Mod Fit LT software (Verity Software House, Topsham, ME). 


\section{Immunofluorescence assay}

PCa cells $\left(2 \times 10^{3}\right)$ were grown on glass-bottom FluoroDish until sub-confluence and treated with AMD3100, CXCL12 and DTX as described above. After treatment cells were fixed in ice-cold methanol, washed, blocked and incubated with glu-tubulin antibody (1:50) for $90 \mathrm{~min}$ at room temperature followed by washing. Cells were then incubated with FITC-conjugated goat anti-mouse secondary antibody (1:500) for $60 \mathrm{~min}$. Thereafter, cells were washed, mounted with antifade Vectashield mounting medium (Vector Labs) and observed under Nikon A1rsi Confocal Microscope System (Nikon Instruments Inc, Melville, NY).

\section{Immunoprecipitation assay}

Total protein from the control and CXCL12-treated PCa cells was collected and estimated using DC Protein Assay Kit (Bio-Rad, Hercules, CA). Subsequently, protein lysates were incubated overnight at $4^{\circ} \mathrm{C}$ with anti- $\alpha$-tubulin (mouse $\mathrm{mAb}$ ) or normal mouse $\mathrm{IgG}$ antibodies (100:1) followed by incubation with Protein A agarose beads (Thermo Scientific, Rockford, IL) for next $2-3 \mathrm{~h}$. Resulting antigen-antibody complex was centrifuged at low speed $(2500 \mathrm{~g})$, washed and eluted. Thereafter, whole cell lysate (input) and immunoprecipitated proteins were subjected to electrophoresis and immunoprobed for $\alpha$-tubulin and LIMK1.

\section{Statistical analysis}

All the experiments were performed at least three times. The data obtained were expressed as 'mean \pm standard deviation' and subjected to unpaired two tailed Student's t-test. A value of $p<0.05$ was considered as significant.

\section{ACKNOWLEDGEMENTS}

We would like to acknowledge the funding support from Department of Defense [PC110545 (to APS)], NIH/NCI [CA137513, CA167137, CA175772, CA185490 (to APS) and CA169829, CA186233 (to SS)] and USAMCI.

\section{Conflict of interest}

No potential conflict of interest to disclose.

\section{REFERENCES}

1. Siegel R, Ma J, Zou Z, Jemal A. Cancer statistics, 2014. CA Cancer J Clin. 2014; 64:9-29.

2. Cooperberg MR, Moul JW, Carroll PR. The changing face of prostate cancer. J Clin Oncol. 2005; 23:8146-51.
3. Feldman BJ, Feldman D. The development of androgen-independent prostate cancer. Nat Rev Cancer. $2001 ; 1: 34-45$.

4. Petrylak DP, Tangen CM, Hussain MH, Lara PN, Jr., Jones JA, Taplin ME, Burch PA, Berry D, Moinpour C, Kohli M, Benson MC, Small EJ, Raghavan D, et al. Docetaxel and estramustine compared with mitoxantrone and prednisone for advanced refractory prostate cancer. $\mathrm{N}$ Engl J Med. 2004; 351:1513-20.

5. Tannock IF, de WR, Berry WR, Horti J, Pluzanska A, Chi KN, Oudard S, Theodore C, James ND, Turesson I, Rosenthal MA, Eisenberger MA. Docetaxel plus prednisone or mitoxantrone plus prednisone for advanced prostate cancer. N Engl J Med. 2004; 351:1502-12.

6. Amos LA, Lowe J. How Taxol stabilises microtubule structure. Chem Biol. 1999; 6:R65-R69.

7. Seruga B, Ocana A, Tannock IF. Drug resistance in metastatic castration-resistant prostate cancer. Nat Rev Clin Oncol. 2011; 8:12-23.

8. Mimeault M, Johansson SL, Vankatraman G, Moore E, Henichart JP, Depreux P, Lin MF, Batra SK. Combined targeting of epidermal growth factor receptor and hedgehog signaling by gefitinib and cyclopamine cooperatively improves the cytotoxic effects of docetaxel on metastatic prostate cancer cells. Mol Cancer Ther. 2007; 6:967-78.

9. Zelivianski S, Spellman M, Kellerman M, Kakitelashvilli V, Zhou XW, Lugo E, Lee MS, Taylor R, Davis TL, Hauke R, Lin MF. ERK inhibitor PD98059 enhances docetaxel-induced apoptosis of androgen-independent human prostate cancer cells. Int J Cancer. 2003; 107:478-85.

10. Gottesman MM, Fojo T, Bates SE. Multidrug resistance in cancer: role of ATP-dependent transporters. Nat Rev Cancer. 2002; 2:48-58.

11. Ploussard G, Terry S, Maille P, Allory Y, Sirab N, Kheuang L, Soyeux P, Nicolaiew N, Coppolani E, Paule B, Salomon L, Culine S, Buttyan R, et al. Class III beta-tubulin expression predicts prostate tumor aggressiveness and patient response to docetaxel-based chemotherapy. Cancer Res. 2010; 70:9253-64.

12. Meads MB, Gatenby RA, Dalton WS. Environment-mediated drug resistance: a major contributor to minimal residual disease. Nat Rev Cancer. 2009; 9:665-74.

13. Akashi T, Koizumi K, Tsuneyama K, Saiki I, Takano Y, Fuse H. Chemokine receptor CXCR4 expression and prognosis in patients with metastatic prostate cancer. Cancer Sci. 2008; 99:539-42.

14. Arora S, Bhardwaj A, Singh S, Srivastava SK, McClellan S, Nirodi CS, Piazza GA, Grizzle WE, Owen LB, Singh AP. An undesired effect of chemotherapy: gemcitabine promotes pancreatic cancer cell invasiveness through reactive oxygen species-dependent, nuclear factor kappaB- and hypoxia-inducible factor 1alpha-mediated up-regulation of CXCR4. J Biol Chem. 2013; 19: 21197-207. 
15. Singh S, Srivastava SK, Bhardwaj A, Owen LB, Singh AP. CXCL12-CXCR4 signalling axis confers gemcitabine resistance to pancreatic cancer cells: a novel target for therapy. Br J Cancer. 2010; 103:1671-9.

16. Arya M, Patel HR, McGurk C, Tatoud R, Klocker H, Masters J, Williamson M. The importance of the CXCL12-CXCR4 chemokine ligand-receptor interaction in prostate cancer metastasis. J Exp Ther Oncol. 2004; 4:291-303.

17. Kukreja P, Abdel-Mageed AB, Mondal D, Liu K, Agrawal KC. Up-regulation of CXCR4 expression in PC-3 cells by stromal-derived factor-1alpha (CXCL12) increases endothelial adhesion and transendothelial migration: role of MEK/ERK signaling pathway-dependent NF-kappaB activation. Cancer Res. 2005; 65:9891-8.

18. Taichman RS, Cooper C, Keller ET, Pienta KJ, Taichman NS, McCauley LK. Use of the stromal cellderived factor-1/CXCR4 pathway in prostate cancer metastasis to bone. Cancer Res. 2002; 62:1832-7.

19. Domanska UM, Timmer-Bosscha H, Nagengast WB, Oude Munnink TH, Kruizinga RC, Ananias HJ, Kliphuis NM, Huls G, De Vries EG, de Jong IJ, Walenkamp AM. CXCR4 inhibition with AMD3100 sensitizes prostate cancer to docetaxel chemotherapy. Neoplasia. 2012; 14:709-18.

20. Nehme A, Varadarajan P, Sellakumar G, Gerhold M, Niedner H, Zhang Q, Lin X, Christen RD. Modulation of docetaxel-induced apoptosis and cell cycle arrest by alltrans retinoic acid in prostate cancer cells. $\mathrm{Br} \mathrm{J}$ Cancer. 2001; 84:1571-6.

21. Kavallaris M. Microtubules and resistance to tubulinbinding agents. Nat Rev Cancer. 2010; 10:194-204.

22. Ahmed AA, Wang X, Lu Z, Goldsmith J, Le XF, Grandjean G, Bartholomeusz G, Broom B, Bast RC, Jr. Modulating microtubule stability enhances the cytotoxic response of cancer cells to Paclitaxel. Cancer Res. 2011; 71:5806-17.

23. Nishita M, Aizawa H, Mizuno K. Stromal cell-derived factor 1alpha activates LIM kinase 1 and induces cofilin phosphorylation for T-cell chemotaxis. Mol Cell Biol. 2002; 22:774-83.

24. Prudent R, Vassal-Stermann E, Nguyen $\mathrm{CH}$, Pillet $\mathrm{C}$, Martinez A, Prunier C, Barette C, Soleilhac E, Filhol O, Beghin A, Valdameri G, Honore S, Aci-Seche S, et al. Pharmacological nhibition of LIM kinase stabilizes microtubules and inhibits neoplastic growth. Cancer Res. 2012; 72:4429-39.

25. Dan C, Kelly A, Bernard O, Minden A. Cytoskeletal changes regulated by the PAK4 serine/threonine kinase are mediated by LIM kinase 1 and cofilin. J Biol Chem. 2001; 276:32115-21.

26. Hatano K, Yamaguchi S, Nimura K, Murakami K, Nagahara A, Fujita K, Uemura M, Nakai Y, Tsuchiya M, Nakayama M, Nonomura N, Kaneda Y. Residual prostate cancer cells after docetaxel therapy increase the tumorigenic potential via constitutive signaling of CXCR4, ERK1/2 and c-Myc. Mol Cancer Res. 2013; 11:1088-100.

27. Kasina S, Macoska JA. The CXCL12/CXCR4 axis promotes ligand-independent activation of the androgen receptor. Mol Cell Endocrinol. 2012; 351:249-63.

28. McGrogan BT, Gilmartin B, Carney DN, McCann A. Taxanes, microtubules and chemoresistant breast cancer. Biochim Biophys Acta. 2008; 1785:96-132.

29. Vicente-Manzanares M, Cabrero JR, Rey M, Perez-Martinez M, Ursa A, Itoh K, Sanchez-Madrid F. A role for the Rho-p160 Rho coiled-coil kinase axis in the chemokine stromal cell-derived factor-1alpha-induced lymphocyte actomyosin and microtubular organization and chemotaxis. J Immunol. 2002; 168:400-10.

30. Kwong J, Kulbe H, Wong D, Chakravarty P, Balkwill F. An antagonist of the chemokine receptor CXCR4 induces mitotic catastrophe in ovarian cancer cells. Mol Cancer Ther. 2009; 8:1893-905.

31. Bhat KM, Setaluri V. Microtubule-associated proteins as targets in cancer chemotherapy. Clin Cancer Res. 2007; 13:2849-54.

32. Haddad E, Zugaza JL, Louache F, Debili N, Crouin C, Schwarz K, Fischer A, Vainchenker W, Bertoglio J. The interaction between Cdc42 and WASP is required for SDF-1-induced T-lymphocyte chemotaxis. Blood. 2001; 97:33-8.

33. Radu M, Semenova G, Kosoff R, Chernoff J. PAK signalling during the development and progression of cancer. Nat Rev Cancer. 2014; 14:13-25.

34. Park MH, Lee HS, Lee CS, You ST, Kim DJ, Park BH, Kang MJ, Heo WD, Shin EY, Schwartz MA, Kim EG. p21Activated kinase 4 promotes prostate cancer progression through CREB. Oncogene. 2013; 32:2475-82.

35. Ahmed T, Shea K, Masters JR, Jones GE, Wells CM. A PAK4-LIMK1 pathway drives prostate cancer cell migration downstream of HGF. Cell Signal. 2008; 20: $1320-8$.

36. Bhardwaj A, Singh S, Srivastava SK, Arora S, Hyde SJ, Andrews J, Grizzle WE, Singh AP. Restoration of PPP2CA expression reverses epithelial-to-mesenchymal transition and suppresses prostate tumour growth and metastasis in an orthotopic mouse model. Br J Cancer. 2014; 110:2000-10.

37. Arora S, Bhardwaj A, Srivastava SK, Singh S, McClellan S, Wang B, Singh AP. Honokiol arrests cell cycle, induces apoptosis, and potentiates the cytotoxic effect of gemcitabine in human pancreatic cancer cells. PLoS One. 2011; 6:e21573.

38. Bhardwaj A, Singh S, Srivastava SK, Honkanen RE, Reed E, Singh AP. Modulation of protein phosphatase 2A activity alters androgen-independent growth of prostate cancer cells: therapeutic implications. Mol Cancer Ther. 2011; 10. 